\title{
Predicting the future
}

\section{What does academic librarianship hold in store?}

\author{
by Carla Stoffle, Barbara Allen, Janet Fore, and Emily R. Mobley
}

\section{Reinventing academic libraries and librarianship}

\author{
by Carla Stoffle, Barbara Allen, and Janet Fore
}

I revel in the present. I believe that this is the greatest time ever to be a librarian. I believe we should celebrate our past successes, but I do not believe that these will suffice to give us the guidance we need for creating the future. I am optimistic about our future, but I don't have much of a concrete sense of what libraries and librarians will be doing even ten years from now, except that it will be radically different. However, it is clear to me that how we respond to the challenges and opportunities of today will determine not only the future of librarianship but also many aspects of the future of our institutions and the wider society.

I am a person who has confidence in the philosophy, values, and talents of librarians. I believe we will respond appropriatelythe future is safe with us. And it is within this context that I will address the topic of challenges and opportunities.

Today's challenges create a dynamic environment unlike any that academic librarians have ever experienced. For this reason, it has become necessary for librarians to reinvent ourselves so we can best serve our communities. It is my belief that given our skills, experience, values, and philosophical framework, librarians perform a unique and essential role in shaping the culture and communities in which we participate.

That is why we are duty bound to step up and take leadership in our learning communities-not just to save the library, but to ensure that the networked, global economy is based on the democratic ideals that have shaped the information environment of the past.

Because academic libraries do not exist in isolation of their insticutions or society at large, let me begin by briefly listing what I think are the most pressing challenges in higher education, especially those that also impact our libraries:

- Demands for accountability (especially creating performance and outcome measures in regard to learning programs).

- Economic pressures (do more with less and create scaleable instructional programs).

- Rapidly changing technology (need to continually upgrade without funds to do so).

- Difficulty recruiting and retaining top talent (salaries).

Ed note: Carla Stoffle and Emily Mobley originally presented these looks at the fiuture at the 2000 ACRL President's Program. We are pleased to share their presentations with this broader audience.

\section{About the authors}

Carla Stoffle is dean of libraries at the University of Arizona, e-mail: cstoffle@bird./ibrary.arizona.edu. She developed this presentation with Barbara Allen, special assistant to the dean, e-mail: allenb@library.bird.arizona.edu, and Janet Fore, team leader of undergraduate services, e-mail: jfore@library.arizona.edu--both of the University of Arizona. Emily R. Mobley is dean of libraries at Purdue University, e-mail: emobley@purdue.edu 
- Changing student demographics and not enough diversity in the faculty and staff.

- Creator's rights in danger of being out of balance with the public good with implications for learning and research programs.

- Pressure to commercialize all information created by the institution.

- Real competition for the educational dollars available.

Additional challenges that directly confront academic libraries today include:

- Continuing unreasonable increases in the cost of information.

- The need to create the new library focused on customers, learning and knowledge management, while maintaining the old library focused on things without new funds.

- Archiving (preserving) and refreshing electronic materials for perpetual access.

- Filtering threats that are emerging from state legislatures.

- Maintaining individual privacy rights in light of security issues raised in the networked environment.

- A need for new measures that demonstrate the "value added" by the library to institutional priorities-learning and research.

- Need for diverse staff who are focused on our customers, flexible, and continual learners.

- Need to strengthen and support our library educational programs.

- Need to respond aggressively to competition inside and outside the academy.

\section{Meeting the challenges}

While I could go into great detail on each of these, the foregoing are well known to all of us. I have to admit that many of these challenges and the opportunities available today are ones that we have been addressing in some form or another off and on for the last decade. We have begun laying a new foundation. We have been reinventing academic libraries. Within the next few years we must cement this new foundation if we, librarians, want to take charge in defining the future of academic librarianship and libraries. So, rather than focus on the challenges, I would like to concentrate on some examples of how we are meeting these challenges and what are the most pressing issues with which we must deal.

We are facing fundamental changes; requiring paradigm shifts to successfully control our own future. I believe we have made a good start. We have a number of collaborative efforts we can point to with pride. However, the core issue is our ability and determination to compete. It is said that "He who controls the playing field, controls the rules." So far, libraries have not been major players in the development of the networked environment, and in our institutions we have been at the end of the learning and research creation processes. Therefore, we are in a defensive position with the rules constantly changing. We are constantly responding to someone else's agenda, rather than to the needs of our customers. To successfully compete, we must leverage our resources, redirect our priorities, collaborate, take risks, and reinvent our organizations Within our institutions we must move to the beginning of the learning and knowledge creation processes becoming partners with the faculty, not just afterthoughts. We must assert our traditional principles and values-seize the high moral ground-and insist that these become the foundation for the new networked playing field. In effect, we must become activists, seize the initiative, and gain control over the "rules" of the new competition.

One set of responses reflecting the foregoing commitment to retake the playing field and the urgency with which we need to act are the Keystone Principles. These principles, conceived by 80 academic librarians in November 1999, and endorsed by ACRL in January 2000 , layout three principles that are rooted in our values:

- Scholarly and government information is a public good and must be available free of marketing bias, commercial motives, and cost to the individual user 
- Libraries are responsible for creating innovative information systems for the dissemination and preservation of information and new knowledge regardless of format.

- The academic library is the intellectual commons for the community where people and ideas interact in both the real and virtual environments to expand learning and facilitate the creation of new knowledge (http:// www.arl.org/training/keystone.html).

The principles and the 22 action items listed provide a values framework that can guide our collective actions and provide a basis for our discussions with potential partners and competitors. They exemplify the kind of actions we must take to create the libraries our customers need. The principles and the action items are idealistic, but realistic in presenting the kinds of actions we must undertake be successful. They build on what we are doing and they call upon us to act in ways that are sometimes difficult due to economic and/ or institutional constraints. They call upon us to be better and to do better than we currently are. They also call upon us to recognize that libraries can no longer go it alone, whether in developing instructional materials, creating knowledge management systems and new access tools, or fighting for users' rights in the networked environment. However, they do give us a new starting point for our collective actions to build the future. They bring coherence and legitimization for many of the activities we have already begun.

\section{Current actions}

I would like to highlight some of our current actions that reflect the values of the principles and which are helping us deal with our challenges while creating the future based on traditional values:

- SPARC, the Scholarly Publishing and Academic Resources Coalition is a prime example of how we have implemented the actions called for in Principles One and Two. SPARC is helping to reduce the cost of information while improving the knowledge products, speed of dissemination, and author's rights. Our collective action is helping us shape the future of scholarly communication (http://www.arl.org/ sparc/home).

- "Create Change," a project of SPARC, ARL, and ACRL to develop tools for local advocacy on scholarly communication issues also is an example of how our collective action can influence the development of new solutions to the challenges of information price increases and copyright restrictions (http:// www.createchange.org/home.html).

- "The Principles for Emerging Systems of Scholarly Publishing" document, issued by AAU and ARL, is a major step forward in asserting the principles under which libraries and their academic communities will approach scholarly communication issues in the future. They clearly articulate a role for libraries in addressing the interests of the scholarly community (http://www.arl.org/scomm/tempe.html).

- The California Digital Library Project (http:www.cdlib.org/), the Library of Congress "America Memory" Project (http://memory. loc.gov/ammem/amhome.html), the National Agriculture Library's Agnic Project (http:// www.agnic.nal.usda.gov/), Columbia University's CIAO (http://www.ciaonet.org), Earthscape Projects (http:/www.earthinstitute. columbia.edu/), and Stanford's HighWire Press (http://highwire.stanford.edu) are examples of different kinds of partnerships that represent library responses to the need to address knowledge creation and knowledge packages that will support research and new learning programs.

- The ARL proposed "Scholar's Portal" represents an opportunity for academic libraries to collectively develop tools and a search engine for a full-service shared Web presence. The development of the Scholar's Portal will be governed by traditional library values and will be a general entry point for all information in our libraries and on the Web. Partners outside the library community who share these values will be sought to actualize such a concept (http://www.arl.org/arl/proceedings/136/ portal.html).

- The ARL "New Measures" Project reflects a commitment to rethinking how academic libraries are defined, managed, and evaluated. Focused on outcome assessment, rather than inputs, the five projects underway reflect the commitment to the future and power of collaborative action. They also reflect a commitment to better manage library resources so that funding can be reallocated to developments necessary for our future libraries (http:// www.arl.org/stats/newmeas/newmeas.html).

- A number of libraries are currently investing in scaleable instructional efforts built on the ACRL Information Literacy Competen- 


\section{We still have services that have}

\section{taken on a "sacred cow" status,}

like face-to-face reference. If we

let go of these "sacred cows," we

would be free to rethink how we create and perform our services.

cies for Higher Education, open source software, and principles of interoperability. The award-winning University of Washington UWIRED (http://www.washington.edu/ uwired/) and University of Arizona RIO (http://www.library.arizona.edu/rio) programs are but two examples of this movement. By sharing in instructional development costs, academic libraries are improving the quality of our information literacy programs and leading the way to new thinking about our instructional efforts.

- SPECTRUM, the ARL Leadership and Career Development Program, the ARL Diversity Fellowships, and myriad minority residency programs (Delaware, Minnesota, Santa Barbara, SUNY-Buffalo) are shining examples of our commitment to diversify our library workforce. They represent how we can take collective action to deal with a major personnel issue in our libraries.

However, lest we get too complacent, we need to recognize that we have just started down the road to building the library of the future. It has taken us a decade to make this start and I fear we do not have another ten years to make the necessary radical and fundamental changes in our organizations, activities, and approaches to work. We still have major gaps. We must take seriously a "customer" focus and design our work and our physical spaces to make our customers more effective, rather than for the convenience of our library employees. We need library workers who are continual learners and who are from diverse backgrounds. We need creativity to address deficiencies in our pay scales so we can compete for the best and the brightest of all college graduates. Our personnel systems need to be revamped to support and reward the kind of employees we need. And we must remember library schools are our partners, we must enhance their viability and encourage their ability to help us with our personnel needs in the new environment.

We still have services that have taken on a "sacred cow" status, like face-to-face reference. If we let go of these "sacred cows," we would be free to rethink how we create and perform our services.

There are several issues that we need to embrace. Filtering, for instance. We are strong and smart enough to confront filtering and the individual privacy issues raised by our networked environment. Academic libraries know that the filtering challenges are not just school and public library issues, therefore, we must participate in these concerns. We are sensitive enough, also, to tackle archiving issues-the technical problems of archiving electronic materials need not take on an exaggerated importance. We are letting archiving questions keep us from needed actions that would accelerate our movement into the networked future.

And there is more I see us providing leadership on: security and authentication, these concerns are important but we cannot erode traditional user access and privacy rights.

\section{Ten axioms to live by}

I will close with some positive things we can do individually to be successful in dealing with today's problems. The following ten axioms have been taken from Jerry Campbell and I believe serve as an excellent guide:

- Evolve/change your core businesses or risk future viability.

- No moral rights are implicit in the old division of labor.

- New windows of opportunity will open.

- New windows of opportunity will be short lived.

- Sure bets will be hard to recognize.

- Your instincts are your best guide, trust yourself.

- Dare to take risks: action cannot wait for painstaking discussion.

- No player exercises master control.

- Whoever acts will create the future.

- Imagine the furure you want and make it real.

\section{Note}

1. Jerry Campbell, "Clinging to Traditional Reference Services," Reference \& User Services Quarterly, 39:3 223-227, 2000) 


\section{The future: Looking for tea leaves to read}

\section{by Emily R. Mobley}

\begin{abstract}
How will the academic libraries of the future look? What changes are in store for the future? What are the signs that may help inform planning for the future? The tea leaves, which we must read, can be found by looking at trends in society, economics, politics, and technology. To see what will impact libraries in the future, we must take a serious look outside of both the library and campus walls.
\end{abstract}

\section{Introduction}

My role is to explore the future. If you're sitting on the edge of your chairs awaiting my prognostications, sit back and relax because I'm going to let you reach your own predictions. What will happen in the future is very fluid and moveable -all we know for sure is that it will not be the same and whatever changes will occur will happen at a rate more rapid than before. As an example of the fluidity and the rapid pace of change, I offer the following statement:

"The Libraries sees great potential for Mosaic to further simplify finding and using diverse library materials, and it has begun to build its work with gopher to provide access to materials through Mosaic. In the coming months, the Libraries will be experimenting with Mosaic as a mechanism for enhanced access to a myriad of useful gopher services now supported on the network."

This was written six years ago. It was about a future which has really come to fruition, but using a technology which has long become (in such a brief span of time) a dead past.

The things that will help shape our futures are occurring today. However, they are occurring outside of our libraries and mostly outside of the walls of academe. By studying the trends, we may be able to predict some possible impacts upon us. I'm going to mention some observations in five areas: political, sociological/cultural, business/financial, technological, and educational. None of these areas are mutually exclusive. It is the interaction and convergence of trends in each of them that contributes to the future which faces us.

\section{Political}

- Continuing trend toward conservatism. It's hard to tell the differences between Republicans and Democrats most days because of the great shift of both parties to the right. The liberal thinking that marked congressional views in the 60 s and 70 s has radically changed and, of course, the results of this swing to conservatism will be felt for many years hence.

- Continuing trend toward anti-big government and taxes. While big government is not one of the key issues for this year's election, it is still with us as a subtheme in other trends. The lowering of taxes is, however, very big, particularly with large surpluses. It's interesting to note that other than Social Security, no one has any interest in improving the lots of the "have-nots" as would have been the case in the $60 \mathrm{~s}$.

- Continuing trend toward importance of local government and greater competition for local dollars. The importance of local government and a resulting competition for local dollars is one result of the anti-big government movement and the shifting of previous federal responsibility to states and filtering down to municipalities. Unfortunately for local governments there has been no easy way to increase needed funds, as was true when the federal government had responsibility. Those of us in state-assisted universities are all too aware of having to lower expectations for funds due to "new" competitors in the state house. This trend will continue for the foreseeable future. More importantly, as these trends interact with others that will be mentioned later, the impact may help shape our institutions in new ways.

- Privatization and computerization of government. The handwriting has been on the wall for some time, but a recent example may give concrete evidence of this trend. If you've attempted to obtain information from the U.S. Passport Office recently, you can see this trend at work. In seeking information last year concerning the renewal of my passport, a telephone recording directed me to a Web site or the option of talking to a human at $x$ cents per minute, billable to my home 


\section{The things that will help shape our}

futures are occurring today.

However, they are occurring

outside of our libraries and mostly

outside of the walls of academe.

phone bill or a credit card. I chose the Web site option and very rapidly I had both the answers to my questions and the application form.

\section{Sociological/cultural}

- Continuing trend toward conservatism. This trend is repeated here because the cultural is helping to drive the same political trend. Also driving this trend is a feeling that change is too rapid, the outcomes have not been good, and a general longing for the good old days.

- Splintering of melting pot due to diversity. The move toward celebrating diversity has also led to less "mixing and melting" and perhaps a lack of articulated focus for American culture

- Changing mores in philanthropy. Younger philanthropists with extraordinary resources are making their impact. Their interests are not the same as their parents. These younger philanthropists are driven by a desire to make a difference in areas they wish to make that difference and at the same time often desire to be active participants. Two good examples are Bill Gates and Phil Knight The old tried and true "asks" don't work with this new generation.

- Continued rise in number of households with computers. Sixty-two percent of households nationwide have computers and, of course, the percentage is much larger in higher socioeconomic brackets. This increase in numbers of home computers will continue to grow fueled by a good economy and the almost total stress on technology and its relationship to a good economy.

- E-business flooding homes through advertisements. You cannot view a program on television without noticing the proliferation of ads with a com presence. As an example, during an NBA Finals game, $75 \%$ of the ads in the first hour had .com presence. There are few, very few, advertisements with a org presence, perhaps a few more with a gov presence, but what seems to be largely missing, unless the ad is about admissions, is a .edu presence. I would hope that this observation is as troubling to you as it is to me.

- Continued rise of anti-intellectualism. This is very troubling, but true, and may go along with the swing away from liberalism. Intellectualism is felt to be akin to liberalism. Along with this movement is a distinct lack of tolerance for new and different ideas. This trend may also be associated with higher education being looked at as the place to get what's needed to get a good job, instead of to obtain a good education

\section{Economics/business}

- E-commerce is where it's at. Not everyone understands what e-commerce is, but everyone is trying to get on board-from real e-commerce to merely having a .com presence. I'm amazed by the number of very small shops, many just "mom and pop" operations who see having a com address as a sign of having arrived. Of course as we are seeing today, there's going to be continuing and rapid shakeouts of real e-commerce companies.

- Rise of .com reference/expert systems. More than $\$ 500$ million in e-reference, expert help, and related systems were funded by venture capitalists in 1997-2000. Does it bother any of you that in many of the advertisements the fact that they have links to the great libraries of the world is stated?

- Trend toward more e-publishing. Even though e-books are predicted to garner only about $5 \%$ of the market within the next few years, this is clearly a trend to pay very close attention to, particularly the business models being tried. Publisbers Weekly is doing a good job of keeping abreast of developments in e-publishing. Coupled with this is the rapid development of rights manage ment software, which is another trend to pay close attention to.

- Rise of contract law in lieu of copyright. Anyone, and I think we all are, dealing with the negotiation of contracts for digital products is quite aware of this trend and the impact. The real question is, are we looking far enough out into the future to see what we may be inadvertently setting ourselves up 
for when we are truly working in a digital environment?

- Mergers/acquisitions in information industry will accelerate in near future. We've seen a history of this in the print publishing industry. It is really just beginning with the digital component. I don't believe you should look upon the recent acquisition of Endeavor by Elsevier as an anomaly, for it is very likely the harbinger of things to come.

\section{Technological}

As a profession, we've been doing a good job keeping up with technological trends, so I've chosen not to spend much time on this area, thus I'll merely present these two trends as critical for libraries.

- One billion people will be connected to the Internet by 2005 .

- Technological advances related to information storage and manipulation will accelerate.

\section{Education}

- Trend toward commercialization of intellectual property rights is running counter toward the push for free access to printed intellectual property. I've been watching these two issues with great interest because intellectual property has seemingly been split into two dichotomies within the academy. On the one hand, research institutions are increasing their efforts to secure patents for developments and thus gain dollars from licensing for those developments and inventions that are highly marketable. On the other hand, driven by the high cost of scientific journals, there is a push to use technology to provide avenues of free access to what has traditionally been printed intellectual property. I don't wish to take anymore time on this, as a number of other issues could be raised, but I did want to point out that it is an interesting dual trend.

- Continued competition for dollars for/within the academe. I don't believe much more needs to be said here because this trend has been going on for some time. It is here not because it is new, but because it will continue and due to the convergence of a number of trends mentioned throughout this talk, the competition may become even fiercer than in the past.
- Continuing demand for accountability. This trend is true for $\mathrm{K}-12$ as well as higher education. It is starting to have a serious impact on institutions, particularly stateassisted ones. You can expect that this will filter down through all units within the university, including the library. We're just starting to pay serious attention to outcome measurements (example: current ARL initiatives). The days of using collection size as the primary indicator of "quality" are about to be over.

- Continued push for access through distance education. This is really just becoming an issue for "elite" institutions, but has been institutionalized at a number of other institutions. It is essentially being driven today from competition or perceived competition from commercial entrants (e.g., University of Phoenix). I don't think much mention is needed in regards to the impact on libraries, particularly on those who historically have not served distant populations.

\section{Impact on libraries}

Librarianship is alive and well but will continue to undergo significant change. Our value system of the public good of information is under attack on a variety of fronts and unfortunately the trends do not indicate any abatement. While talks of ethnic diversity in library staffing are important, the real diversity which academic libraries are encountering is the diversity in jobs needed to run such complex organizations. More and more of these positions are falling outside of the MLS umbrella. We are already running two different libraries-one traditional and one digital. The easy convergence of these two may be next to impossible in the near future. Libraries are becoming collaboratories in services, facilities, and staffs.

Reading the trends or the tea leaves may be more of an art than a science, however systematic thinking is vital for success. I would recommend reading a book by Dietrich Dorner, The Logic of Failure, first published in Germany in 1989, with an English translation published in $1996 .{ }^{1}$ Although the book is not about trend analysis, the examples provide wonderful illustrations of the challenges of acting in complex systems, and we can truly say that what is being faced in academic libraries today is a very complex environment. 
Reading the tea leaves does require us to look outward and seriously consider possible impacts. The challenge is that the interaction of the various trends creates far more complexity in considering the ifs.

At the beginning of this presentation, I said that no prognostications would be offered. However I can't resist giving one. Let's look at one example (an easy one) using some of the trends mentioned, so I'll call this an Emily prognostication.

Recently, librarians have been involved in lobbying for more funding for the GPO and the document depository program. Because of trends mentioned in the political arena (e.g., privatization and computerization of government, and anti-big government continued rise in number of households with computers), I believe that the government document depository program is about to be a thing of the past.

\section{Conclusion}

As academic librarians, we need to look outward, study the trends, and prepare for the future rather than being blindsided by it. Further, we need to become more aggressive in working to shift and influence these external trends that lay outside of our usual spheres. Along the way we will also need to evaluate some of our "sacred cows."

\section{Note}

1. Dietrich Dorner, The Logic of Failure, (Massachusetts: Addison-Wesley Longman, 1997).

\title{
t \\ ChoiceReviews.online \\ *
}

It's more than just a database of reviews!

*

$\star$ Access all the CHOICE reviews since September 1988 in a searchable database on the Internet

$\star$ E-mail reviews to your colleagues

$\star$ Receive notification of new reviews fitting your personal profile.

$\star$ Create and modify groups of reviews-Year-end funds, Reference, special subjects, lists by faculty name, etc.

$\star$ Password access allows high degree of customized use

$\star$ SUBSCRIBE NOW for $\$ 395$ ! Annual subscription includes personalized access for up to 20 users and all $\quad \star$ corresponding print issues of the magazine.

\section{Visit us at www.ChoiceReviews.org and click on "Register Now" to sign up for a free trial.}

\author{
Questions? Contact us at (860)-347-6933 $\times 23$ \\ * Or e-mail ChoiceOnline@ala-choice.org. \\ Information available online:
}

Fact sheet: http://www.ala.org/acrl/choice/crofacts.html
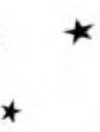

Licensing agreement: http://www.ala.org/acrl/choice/cro-lic.html 